\title{
A systemic perspective on socioeconomic transformation in the digital age
}

\author{
Rita Strohmaier $^{1}$ (D) $\cdot$ Marlies Schuetz ${ }^{1} \cdot$ Simone Vannuccini $^{2}$ D
}

Received: 6 April 2019 / Revised: 29 June 2019 / Accepted: 3 July 2019 / Published online: 22 July 2019

(C) The Author(s) 2019

\begin{abstract}
Digitalization has set the stage for a stream of radical innovations that have the potential to trigger a new technological revolution and cause deep structural changes throughout the economy, affecting not only the technology base, but also the facilitating structure (including production, infrastructure and markets), public policy, and the environment. Focusing on these building blocks, we combine network analysis and composite indicators into a novel framework to investigate a country's socioeconomic system both across its components and over time. Its empirical application to a set of Western and Asian countries over 10 years gives insights into their socioeconomic performance and development, as well as their capability to absorb technological change. A structural decomposition analysis further allows investigating the evolution of countries' structural transformation over time and shows the impact of digitalization and Industry 4.0 in this regard.
\end{abstract}

Keywords Technological change $\cdot$ Socioeconomic transformation $\cdot$ Economic development · Digitalization

JEL Classification $\mathrm{O} 10 \cdot \mathrm{O} 30 \cdot \mathrm{O} 57 \cdot \mathrm{P} 51$

\begin{abstract}
This paper was presented in September 2018 at the EAEPE Conference Nice, and at the ENEF Conference, Sussex. We are very grateful for the valuable comments and remarks we received in this context, which are already partially addressed in this manuscript.
\end{abstract}

Electronic supplementary material The online version of this article (https://doi.org/10.1007/s4081 2-019-00124-y) contains supplementary material, which is available to authorized users.

Rita Strohmaier

rita.strohmaier@uni-graz.at

1 Graz Schumpeter Centre, University of Graz, Graz, Austria

2 Science Policy Research Unit, University of Sussex, Brighton, UK 


\section{Introduction}

It is safe to say that the innovative principle underlying most, if not all, recent technological breakthroughs in areas such as advanced robotics, micro- and nanoelectronics or biotechnology is digitization, the conversion of information from analog to digital. Continuous improvements in "More Moore" and "More-than-Moore" technologies have enabled the pervasive application of this principle to virtually all areas of the economy and society, a trend commonly referred to as digitalization. In this paper, we apply a novel methodology that combines indicators and network theory in order to measure the systemic impact of digitalization. Digitalization induces broad socioeconomic change, setting the stage for a fully-fledged technological revolution, meant as "a set of interrelated radical breakthroughs, forming a major constellation of interdependent technologies; a cluster of clusters or a system of systems" (Perez 2010, p. 189). Indeed, the widely discussed rejuvenation of manufacturing into a "smart manufacturing", or "Industry 4.0", is one of the transformations characterizing the later stage of the digital revolution that according to Carlota Perez (2002) already started out with the invention of the Intel Microprocessor in 1971. What we experience nowadays is the deployment period of this revolution-a potential "golden age" (Perez 2013, p. 11), marked by technological diffusion, dynamic sectoral expansion, and economies of scale. In this crucial phase, entrepreneurship should dominate financial capital while institutions should safeguard strong markets and social well-being. However, such golden age lies on a path of creative destruction and destructive creation that can affect societies in costly ways. Digitalization shapes many aspects of society, not least employment and the future of work, restlessly engaged in a "race against the machine". In fact, beyond the ongoing debate on the "effect size", smart technologies are projected to have vast implications for the labor market (see, for example, Brynjolfsson and McAfee 2014, Autor 2015, Frey and Osborne 2017, Frank et al. 2019). At the international level, innovationleading countries in the Global North are currently facing a race for the machine. In this race, some Asian countries, especially the four Tiger states, are projected to occupy the pole position in the future, as-according to the political scientist Kishore Mahbubani-these economies have acquired the main pillars of Western societies, such as the free market, science, education and the rule of law, whereas the latter have been "gradually walking away from these pillars."

The need to understand the capacity of our socioeconomic systems to tackle the profound changes currently unfolding calls for a systemic perspective on the digital revolution that comprehends technological change as a process shaping and being shaped by social and economic factors. In this context, we developed a tool and a novel indicator to grasp and represent the impact of the digital age on the interdependent structural components of contemporary socioeconomic systems.

Our motivation is thereby twofold: On the one hand, to complement the systemic approaches in the literature on technological revolutions with an empirically

\footnotetext{
${ }^{1}$ http://www.chinadaily.com.cn/opinion/2010-12/23/content_11742747.htm (quoted in Reinert et al. 2016).
} 
tractable framework; on the other hand, to add up to the existing toolkit of assessing social and economic development by taking into account the linkages between different pillars of the socioeconomic system. While we do consider digitalization a stage of the latest technological revolution, our aim is neither to provide a measurement of the longue durée of technologically driven transformations nor to supplement Long Wave theory with a less historical and more quantitative approach. Contrarily, we aim at obtaining a snapshot of the structural effects of the digital transformation 'in the making' on socioeconomic systems. Our contribution is to use a novel methodology to envelop the complexity of change as it percolates over the socioeconomic structure, rather than digging into its ultimate determinants.

We apply our tool to a set of Western (the innovation leaders in the European Union, namely. Denmark, Finland, Germany, the Netherlands, Sweden, as well as the US) and Asian countries (China, India, Malaysia, Singapore, South Korea and Taiwan) for the period between 2007 and 2016, in order to assess their progress in the main pillars of the socioeconomic system at the presumably first stage of deployment period of smart technologies. In particular, we will try to answer the following questions: (1) What was the impact of digitalization on overall socioeconomic development, what the impact of employment and work organization, and how are they related to the digital transformation? (2) How similar are countries in terms of their absorption pattern of technological change related to the so-called Industry 4.0 ?

The paper proceeds as follows. In Sect. 2, we describe the theoretical background that motivates our systemic approach while in Sect. 3 we briefly sketch the methodological framework and outline related data issues. Section 4 presents and discusses the results, while Sect. 5 summarizes the essence of the paper and provides the reader with concluding remarks.

\section{Theoretical background}

Our systemic perspective on technological change falls in line with, and is very much grounded in, a range of macroeconomic concepts that also treat technology as being embedded in a specific socioeconomic environment (see e.g. Dosi 1982, Freeman et al. 1982, Perez 1983, Mokyr 1990, von Tunzelmann 1997, Lipsey et al. 2005, Geels and Schot 2007, Schot and Kanger 2018). Different from them, we focus on measuring empirically how broad building blocks of the socioeconomic system and their interrelation drive a country's performance and its capacity for transformation. This quantitative assessment of multidimensional phenomena is usually based on composite indicators or indices. Recently, indices have gained a vital momentum for investigating today's transformations, such as the Global Connectivity Index from Huawei (2019) or the EU Digital Transformation Board (EC 2018). These indices do not only relate to the technology sphere, as, for instance, the Global Competitiveness Index (Schwab and Sala-i-Martin 2017) measures important drivers of a country's productivity, or the Global Entrepreneurship Monitor (GEM consortium 2016) focuses on entrepreneurial activity. While the latter examples are largely based on soft (or survey) data, other indices, such as the Environmental Performance Index 


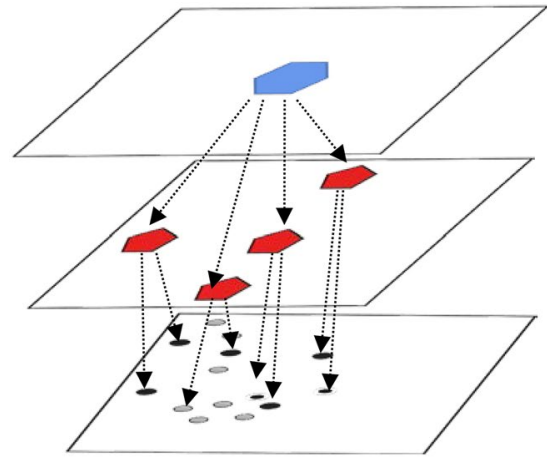

(a)

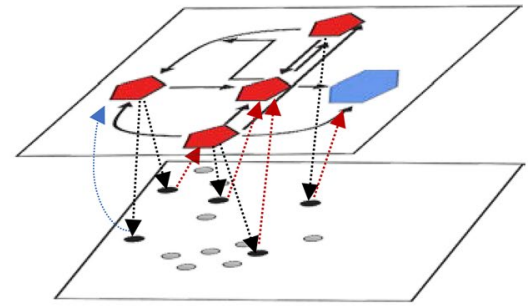

(b)

Fig. 1 a Measuring components of a system as aggregates of their underlying indicators (black nodes)/ subindices (pentagons) versus $\mathbf{b}$ measuring components of a system by the strength of their linkages to all other components in the network. Authors' own illustration

(Hsu and Zomer 2016) use hard data. Indices, by their very nature, can capture the multidimensional aspects of a phenomenon and are important sources for empirical analysis (see Hartmann et al. 2017 and Peris-Ortiz et al. 2018 for two recent examples); however, the vertical aggregation of a diverse set of indicators to composite indicators of increasingly higher order (see Fig. 1a) does not reflect the interaction between these multiple components. By adopting a network approach instead (see Fig. 1b), we use the single indicators to measure the strength of the relation between any two components in the system. By doing so, not only the direct linkages (as depicted by the arrows in the second layer of the figure) are considered, but also the indirect linkages can be accounted for. The overall composite indicator (illustrated by a hexagon in Fig. 1) is thus not derived from a vertical aggregation of indicators along a hierarchical structure but is the result of vertical integration of the strength of its components. The method used to derive this framework is further described in the following section. A detailed discussion of our methodical approach can be found in Strohmaier et al. (2019).

\section{Methods and data}

As outlined above, the process of technological transformation necessarily implies change and coordination in a set of activities and interconnected subsystems. In their structuralist-evolutionary (SE) framework, Lipsey (1999) and Lipsey et al. (2005) suggest how the different components in a socioeconomic system interact with each other. According to the authors, the evolution of technological knowledge-as one component of the SE-structure-therefore shapes and is shaped by the other components in the socioeconomic structure (see the network in Fig. 2a and Lipsey et al. 2005, p. $56 \mathrm{ff}$ ): (1) the facilitating structure, that incorporates the actualizations of technological knowledge and facilitates the various processes in the system (related 


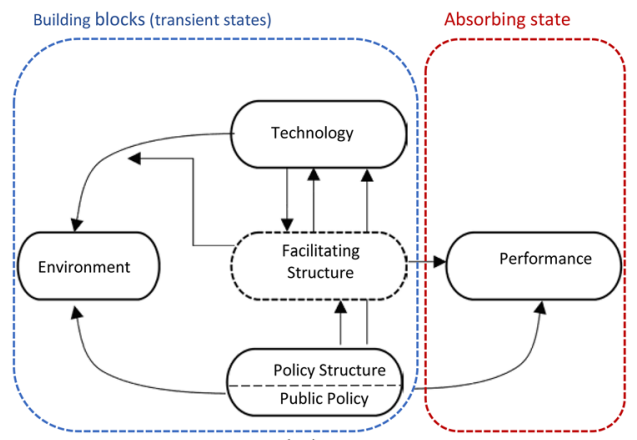

(a)

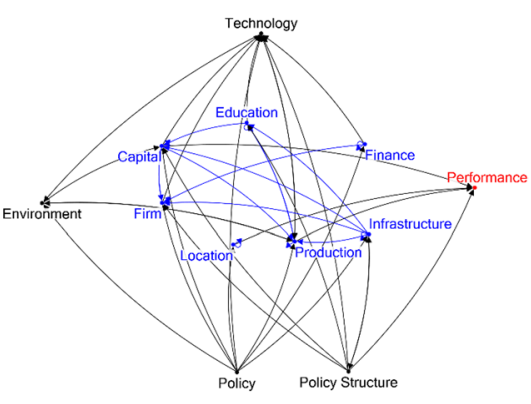

(b)

Fig. 2 a Scheme of the structuralist-evolutionary approach by Lipsey et al. (2005, p. 56, simplified) and b the empirical application of the SE-scheme for a specific country. Authors' own illustration

to, e.g., innovation, production, infrastructure, etc.), (2) public policy, i.e. the policy goals (inherent in legislation, laws, rules, regulations, procedures, and precedents) and the demand and command structure of public bodies, (3) policy structure, that comprises all public sector institutions, including parliament, courts, civil services and regulatory bodies, (4) natural endowments, i.e. basic and raw materials used in the production process; the interplay between all these components determine (5) the overall performance of the economy (in terms of output, employment, etc.).

These components form the nodes of the network presented in Fig. 2a, where the directed edges show the relations between them through which change percolates: Technological knowledge affects a country's (socioeconomic) performance via its ties to the facilitating structure (i.e. the organization of production in broad terms) and its effects on the environment and natural resources. The more radical the technological change, the more profound is its impact on these building blocks; on the other hand, the more supporting the facilitating structure-and the policies and public institutions that affect it - the more likely is the emergence and adoption of a new technological breakthrough.

We make use of the proposed scheme as shown in Fig. 2a for a quantitative assessment of socioeconomic performance as a multidimensional measure of a country's wellbeing. We then investigate how this measure has changed since 2007 and to what extent the present technological trends contributed to these changes. Given nowadays the broad availability of data, we use (survey and non-survey based) information on economic and social aspects and current technological trends to calculate the strength of each building block as the sum of its direct and indirect linkages to the other components in the system. Our quantitative approach is in stark contrast to the way Lipsey et al. (2005) apply their framework, namely in providing a rich historical account of past technological revolutions and their impact on long-term economic development. Instead, we zoom into a short period within the digital revolution and focus on regional differences in the socioeconomic system. While this approach gives tangible insights into the different development paths of countries, it cannot—and does not intend to-picture the full complexity involved in 
economic evolution. Rather, it is meant to be a first stocktaking of structural transformation in the light of disruptive technological change and a lower-bound measurement of the impact technological change can have while percolating through different networks representing different configurations of the structural pillars of a socioeconomic system.

In order to measure the ties between components in the SE-system, we make use of two-mode (or bipartite) networks (see, e.g., Borgatti and Everett 1997, Guillaume and Latapy 2006, Zweig and Kaufmann 2011, or Everett and Borgatti 2012) connecting structural components through underlying dimensions (proxied by indicators) characterizing them. Each of the five components in Fig. 2a (the primary nodes of the bipartite graph, represented by pentagons in Fig. 1b) reflects a diverse range of dimensions (the secondary nodes of the bipartite graph, illustrated by black dots in Fig. 1b). The arrows in Fig. 1b pointing from the pentagons to the black dots therefore show the ties between a source component and its dimensions, the latter of which can be measured by indicators. In addition, each single indicator may also relate to another component (shown by the arrow pointing towards the pentagons in Fig. 1b). The number of patents in environment-related technologies, for example, informs on the technology base of an economy, but also relates to the environment. It is therefore possible to transform this two-mode network of components and dimensions (as illustrated in Fig. 1b) into a one-mode network of components only where the weight of each edge equals the aggregated weights of the underlying dimensions.

Data The empirical application of the SE-structure captures, instead of the five components displayed in Fig. 2a, 12 components in total (see Fig. 2b). This is because we split the facilitating structure further into the following components: (1) capital (comprising all physical, human, health, and social capital); (2) the managerial and financial organization of the firm; (3) location and concentration of industries; (4) the organization of labor and production facilities; (5) infrastructure (including energy, transport and telecommunication); (6) financial markets and instruments; and (7) educational and research institutions. This SE-structure is set up for each of the selected Asian and Western countries and each year over the period of 2007-2016, measuring the 47 edge weights of the network by means of 162 indicators from a variety of data sources (most important, Global Competitiveness Index, Global Entrepreneurship Monitor, Environmental Performance Index, World Development Indicators, OECD, ILO, etc.). As a result of the one-mode projection of the two-mode network, each edge represents a composite indicator and thus needs to comply with the respective technical requirements for index composition. In this regard, we relied on the 10-step procedure proposed in the OECD manual (2008), including multiple data imputation, transformation of scalar values onto a common scale, the treatment of outliers, and a thorough sensitivity analysis to assess the explanatory power and robustness of the indices.

After feeding the SE-structure with data and projecting the indicators to the component level, the resulting network is reinterpreted as a time-homogenous Absorbing Markov Chain (AMC), in order to analyze the relations between components in the socioeconomic system (see, e.g., Kemeny and Snell 1976). We make use of the concept of AMCs to analyze changes in the socioeconomic system as a chain, that is, a sequence of states that depends on the transition probabilities (the likelihood to move from one particular state to another). In this way, the SE-structure is 
conceived as a process where the building blocks of the socioeconomic system (see Fig. 2a)-representing the transient states in the AMC - interact with each other to achieve a particular performance result-representing the absorbing state in the AMC. In the context of the SE-structure, these transition probabilities are captured by the strength of the relations between components (see Harary and Lipstein 1962 for a graph-theoretical interpretation of stationary Markov chains). From this, we obtain (1) a measure of the structural significance of a building block, derived from its position in the network (a priori postulated by the SE-scheme) and the weights of its ties to the other building blocks ${ }^{2}$ and (2) the overall performance of the system, that we label the Socioeconomic Performance Index $\left(\mathrm{SE}^{*} \mathrm{PI}^{3}\right)$, defined as the sum of the total (direct and indirect) linkages between the building blocks and performance. In order to compare this index across countries, each national SE-structure is set to a hypothetical benchmark prior to its assessment within the AMC framework. ${ }^{4}$

In a last step, we carry out a structural decomposition analysis (SDA) for tracing the changes over time back to each single component and its underlying dimensions (see Miller and Blair 2009 for a description in the context of input-output modeling). This allows us to measure the impact of digitalization (conceived as a specific bundle of indicators) on the evolution of the socioeconomic system.

\section{Results and discussion}

In the following, we apply the framework outlined above to a set of Western and Asian countries in order to assess, first, the evolution of their socioeconomic performance (as measured by the SE*PI) between 2007 and 2016 and then analyze the role of digitalization in this context. Finally, we sketch the impact of technological changes related to Industry 4.0 on the socioeconomic structure of these countries.

Figure 3 shows how the countries in the sample evolved over time in terms of their socioeconomic performance. In order to facilitate the comparison between countries, the SE*PI of each economy is shown relative to the performance of the top-ranking country in 2007, Sweden. The shaded areas display the range between

\footnotetext{
${ }^{2}$ Formally, the AMC is captured by the following equation: $B=(I-Q)^{-1} R=N R$, with $\mathrm{Q}$ showing the direct relation between transient states, and $\mathrm{R}$ presenting the direct linkages between the transient states and the absorbing state. The row sums of the fundamental matrix $N$ capture the absorbing time (Harary and Lipstein 1962) - the expected number of periods before a process starting in a specific transient state ends up in the absorbing state. This vector thus represents the total, direct and indirect, linkages between the building blocks and performance and (in its normalized form) is used in our study to measure the significance of the socioeconomic pillars.

3 The asterisk in the acronym should highlight the dual meaning of the first two letters (SE): reflecting, on the one hand, the socioeconomic orientation of the index and, on the other hand, the structural-evolutionary approach the index is based upon.

4 By relating a country's (row-stochastic) transition probability matrix (i.e. the SE-structure) to a hypothetical benchmark, the elements of $B=N R$ become strictly lower than 1. For a specific country, elements in the modified vector $\bar{B}$ thus show the overall significance of a component in the whole system, as expressed by the strength of its linkages to other constituent components as well as its direct effect on economic performance, relative to a global maximum that can be understood as a performance frontier. The sum over all components $i, \sum \bar{b}_{i}$, serves as a scale-sensitive performance measure-the SE*PI.
} 


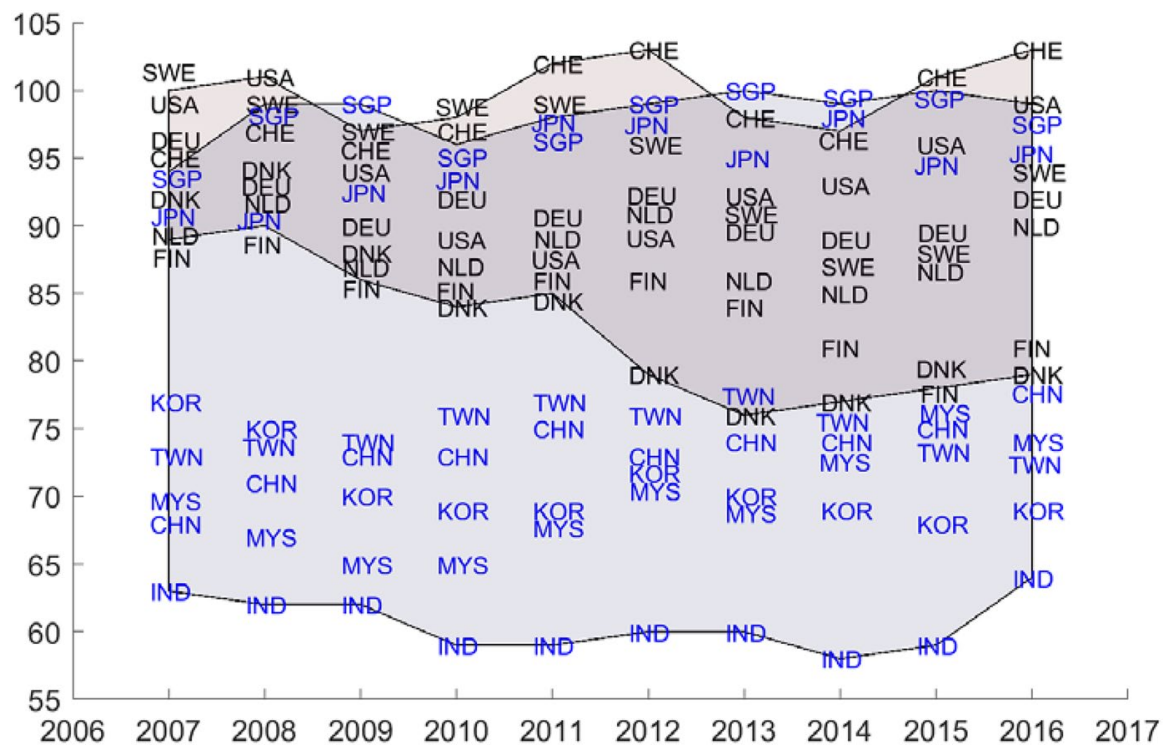

Fig. 3 Relative change in the SE*PI (SWE 2007=100) for selected Western (denoted in black) and Asian (denoted in blue) countries (Denmark (DNK), Finland (FIN), Germany (DEU), the Netherlands (NLD), Sweden (SWE), as well as the United States (USA)) and Asian countries (China (CHN), India (IND), Malaysia (MYS), Singapore (SGP), South Korea (KOR) and Taiwan (TWN)). Authors' own illustration (color figure online)

the best and least performing country in the Western (black) and Asian (blue) subsample, respectively. While there is a large degree of heterogeneity in socioeconomic performance among Asian economies over the whole time span, with Singapore and Japan at the top and India at the bottom of the country group, the Western economies, led by Sweden and the US, were quite close to each other in 2007, but have been diverging since then. Particularly Finland and Denmark have shown a deterioration since the financial crisis of 2008.

Given the pathways each of the countries has shown in the period under study, the question arises whether digitalization reinforced or counteracted this respective development. In all these economies, digitalization has been high on the policy agenda, being actively promoted by public and private institutions, though in different core areas.

In the following, we analyze to what extent the impact of digitalization can be already observed in the data for the country sample and the time period under study. In order to account for the fact that the digital transformation does not only play out on the level of technology, but also in the other building blocks of the socioeconomic system, we isolated the indicators assigned to digitalization (20 out of 162 indicators in total, see Table 1 in "Appendix") from the rest of the variables. Changes in these indicators over time are assumed to reflect the digitalization trend from a broad perspective, not only covering the related changes in infrastructure (e.g. access and quality of broadband), but also in science and education (e.g. use of social networks or internet access in schools), as well as the role of ICT in increasing the competitiveness of a country (e.g. by means of 
patents in this technology field or exports of ICT-related services). By means of SDA, we then calculated the contribution of the selected indicators to changes in the overall socioeconomic performance. The results are shown in Fig. 4, where the changes in the SE*PI, cumulated over the period from 2007 to 2016, are plotted against the cumulated impact of digitalization.

For almost all countries in our sample, digitalization (measured on the vertical axis) had a positive impact on socioeconomic development. Notable exceptions are Finland, where the strong decrease in ICT service exports and the low impact of ICT on restructuring work life reinforced the overall decline in the SE*PI. This also applies, albeit to a lesser degree, to India and Taiwan. Both countries also experienced lower export rates of ICT services over the years under study, and additionally could not fully exploit the potential of ICT for increasing the participation of citizens and stakeholders in public affairs and decision-making. On the other hand, the economies that could benefit most from digitalization are Switzerland and China, followed by Malaysia and Singapore. All these countries were able to raise their export share of ICT services as well as use ICT for the reorganization of work life (see Table S.1 in the Supplementary Material) and the access to basic services (e.g. healthcare or education). In the case of Denmark, Germany, South Korea, as well as Sweden, digitalization counteracted the overall decline in socioeconomic performance.

A similar analysis can be undertaken regarding the contribution of employment and work-related indicators (represented by 11 variables in our empirical framework) to changes in the SE*PI. Figure 5 shows the five most important factors in this regard among Western countries (panel a) and Asian economies (panel b). Out of all indicators related to employment and work, the impact of ICT on new organizational models (e.g. telework, shared office spaces) was the strongest driver of the SE*PI for the Western economies, while for the Asian countries, this factor ranks

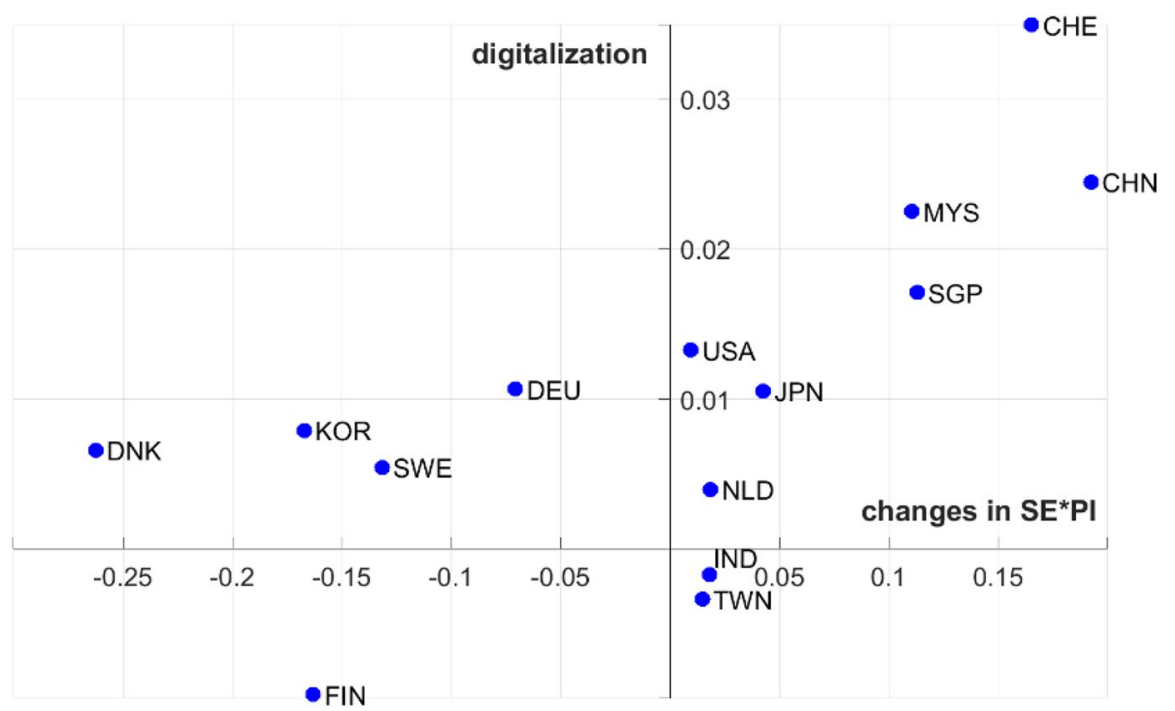

Fig. 4 Cumulative changes in socioeconomic performance and digitalization. Authors' own illustration 


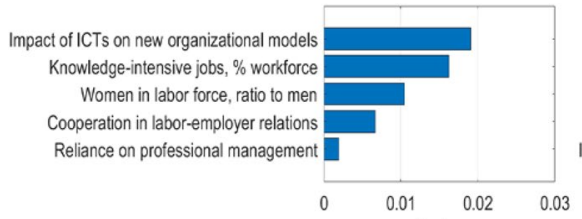

(a)

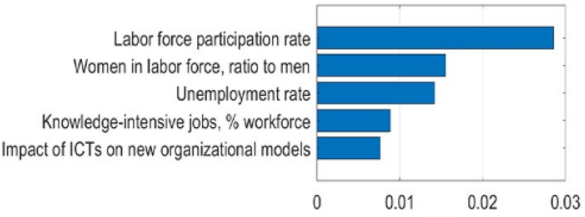

(b)

Fig. 5 Top-5 indicators of employment and work organization contributing to changes in socioeconomic performance, for a Western and b Asian countries. Authors' own illustration

last among the top-5. Another indicator reflecting the current technological trends is the increase of knowledge-intensive jobs in the work force, which again contributed more to socioeconomic progress of the Western than Asian countries. Thus, we see two aspects typically associated with the digital transformation, the reorganization of work and the relative increase of high-skilled labor, to show a stronger manifestation in Western countries compared to Asian ones.

In our analysis, digitalization is tackled as part of the socioeconomic structure, shaping different building blocks and transforming the system from within. While aspects such as broadband bandwidth and the penetration of ICT in private businesses and public services are useful indicators of the digital transformation of economy and society, the digital transformation of industries, i.e. Industry 4.0, goes beyond these general factors. It is usually characterized by technologies enabling high connectivity (via cloud services) as well as the digitization of physical assets and the value chain (via big data analytics and Internet of Things (IoT)) and it strongly relies on data center equipment and services. We extend the existing network model by adding indicators on the supply and demand of these technology trends in 2016 (available from the Global Connectivity Index (Huawei 2019)). The four supply indicators (based on estimated investments in these technologies) are introduced as enhancing either the productive capital of firms (data centers, big data and IoT) or the overall infrastructure (cloud) in the respective economy. Firms then employ these technologies in the production of their goods and services, the degree to which they are utilized is measured by further four indicators (see Fig. 6 as well as Table 2 in the "Appendix"). ${ }^{5}$

By applying a hierarchical clustering algorithm, we grouped the selected countries according to their structural similarities. ${ }^{6}$ The corresponding polar dendrogram for the year 2016, illustrated in Fig. 7, reveals five clusters: a group of structurally heterogeneous Asian economies (China, forming a cluster on its own, as well as India, Korea) faces a cluster of innovation-leading Western and Asian countries. The latter can be further split into six clusters: One containing two Scandinavian economies, Denmark and Sweden; one consisting of the remaining European countries (Finland, Germany,

\footnotetext{
5 Note that the consideration of new secondary nodes (viz. indicators) affects the number and weight of edges in the network and therefore does not allow any longer a direct comparison of the old and the new socioeconomic structure.

6 We used complete-linkage clustering as method and the cosine index as the underlying distance measure. The average silhouette index for 2016 equals 0.6175 . The cophenetic correlation measuring the goodness-of-fit of the chosen algorithm equals 0.7360 .
} 


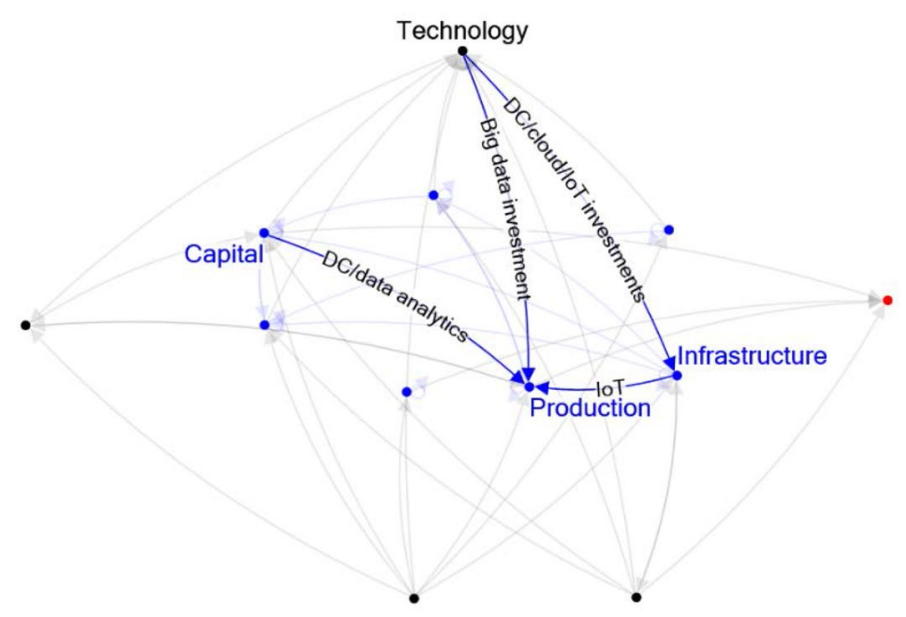

Fig. 6 Modified SE-scheme, extended by the following eight indicators on Industry 4.0 technologies: data center (DC) investments, cloud investments and IoT investments; big data investments; IoT installed base; data center equipment and analytics data creation. See Table 2 for a short description of these indicators. Authors' own illustration

the Netherlands, and Switzerland), a group of Asian frontrunners (Japan, Malaysia, and Singapore); as well as the US that shares some similarity with the former two clusters. Note that the consideration of Industry 4.0 did not change the dendrogram significantly. The only countries that switched clusters are Japan (without the inclusion of the respective indicators joining the group of European countries), and the US (that was before clustered with Malaysia and Singapore).

What are the main empirical takeaways of our analysis? Regarding the evolution of the socioeconomic structure, Denmark and Finland have shown a notable deterioration. Despite the fact that they were at the forefront of ICT innovation and diffusion in Europe from the 1980s onwards, they seem to face obstacles in the current digital wave, which are especially related to access to finance and entrepreneurial culture. These are decisive factors for the digital transformation of the economy and society and, in light of the national initiatives recently launched, are already addressed by policymakers. Moreover, the last decade has experienced a strong catch-up process by the Asian economies, which was driven also by digitalization. As Fig. 4 reveals, Asia could exploit the potential of digitalization more than the Western countries. This might also be linked to the global financial crisis from which Europe is still recovering. The improvement in labor force participation and employment rates contributed to the overall increase of socioeconomic performance of the Asian countries, whereas the impact of digitalization on work organization has gained higher momentum in Western countries. Finally, the decline in ICT service exports in India and the respective rise in Western countries such as Sweden may already point towards re-shoring of production activities at least as far as advanced knowledge services are concerned. The consideration of Industry 4.0 trends further shows a stronger geographical agglomeration of countries, where a group of factor-driven Asian countries is catching up on a set of innovation-driven Western and Asian economies. 


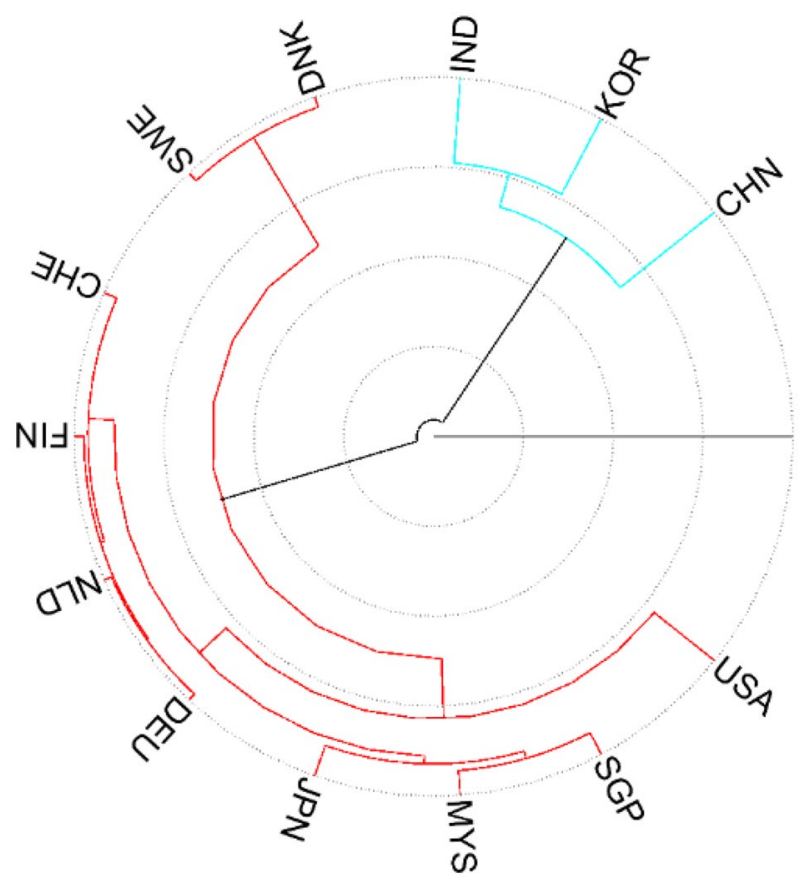

Fig. 7 Similarity in the socioeconomic structure of the selected Western and Asian countries (including Industry 4.0 indicators); reference period: 2016. Authors' own illustration

\section{Reflection and conclusion}

Measuring the next technological revolution on the macro scale exhibits a lot of uncertainty as we tackle a phenomenon that has simply not yet deployed all of its transformational potential. The investigation of countries' capability to absorb a technological transformation certainly needs a multidimensional approach that also takes the interrelation between these very dimensions into account. In this paper, we introduced a framework that can cope with these feedback effects. Acknowledging that most indicators have a direction-i.e. point to dimensions other than the one they are assumed to reflect—and measure the strength of the components by the ties of its underlying indicators to other components, is a novel approach for investigating transformation processes in the economy and society. The SE-tool thereby allows a consistent analysis of a country's socioeconomic system both across its building blocks (the structuralist aspect) and over time (the evolutionary perspective).

We used the SE-tool to compare and cluster countries with respect to the way in which a technological transformation in the making, such as digitalization, percolates through the socioeconomic structure. In this sense, our focus was not on capturing the dynamics of digitalization as a technological phenomenon per se but as a techno-social construct the evolution of which is subject to the structural capacity of economies. From this perspective, the SE*PI indicator condenses the interaction of 
the main pillars of the socioeconomic system into a standardized indicator that can be compared and tracked over time.

Our approach is inclusive in the sense that it covers a wide spectrum of components (including the environment) and investigates their centrality in the network. In this way, it differs from conventional indices that analyze each component separately and then merge them by means of appropriate aggregation procedures.

However, as every empirical framework, our model also inhibits some methodological challenges mainly linked to causality and the fact that edge weights of the network themselves constitute composite indicators and are therefore subject to further scrutiny outside of graph theory. The issue of causality concerns both "layers" of the network: On the one hand, we used the SE-scheme by Lipsey et al. (2005) as a "blueprint" for the type of interaction among the building blocks in the socioeconomic system. On the other hand, the choice of indicators that picture these relations and their assignment to a source and target component also implies causality. In order to keep the degree of arbitrariness as low as possible, we only used indicators that are already established as measures for the respective relation of the socioeconomic system. In most cases it was straightforward to identify a source and target node for an indicator. Whenever there was disagreement concerning the classification done individually by the authors, the assignment of a specific indicator was discussed with other colleagues or experts were consulted. Furthermore, we also tried not to violate the original assignment of indicators to similar categories in the databases; for example, indicators of the EPI database were-if appropriate-reclassified in such a way that either the source or the target node reflected "environment and natural resources". For the future, we will consider path analysis as a tool to study the relationships between the different variables.

Regarding the weighting scheme of the edges (that represent composite indicators), the one-mode projection results in a component score that equals the arithmetic average of the underlying variables. This weighting scheme was selected in order to validate our tool against other indices of economic performance (most notably, the Global Competitiveness Index) which also use this aggregation procedure. In further applications of the model, we plan to introduce an alternative weighting method based on factor analysis.

Given that a significant number of indicators comes from the GCI and the GEM, the approach contains a high share of soft data and is biased towards the entrepreneurial perspective of technological transformation. We tried to limit this bias by also including hard data and information that sheds a different light on socioeconomic wellbeing (such as the GINI index). Nevertheless, we believe this drawback is acceptable, all the more as this data provides a good picture of the framework conditions for entrepreneurial activity in the digital era.

Furthermore, the data set was not complete, implying uncertainty issues regarding the reliability of the results. Instead of opting for complete case analysis-which would have implied to delete all variables that are not available over the whole time and country range, thereby significantly reducing the information actually available-or using single imputation methods (by e.g. replacing a missing value of one country by the mean of the values of all other countries regarding the same variable) - thereby reducing the variance in the data set-we chose multiple imputation 
for the treatment of missing data. This means that all findings retrieved from this analysis are actually the result of running the model with ten different datasets that vary only regarding their missing values. We therefore carried out a very thorough data preparation for constructing the model, nevertheless, the uncertainty regarding the reliability of the results cannot be fully eliminated. Additional robustness checks are envisaged to decrease data uncertainty and therefore increase the validity of the model.

Last but not least, the framework is static in the sense that the number of indicators cannot change from one period to the other without distorting the comparison of results over time. The latter issue will be a matter of future research which aims at transforming the approach into a dynamic network model, where old indicators which have lost their informative value (e.g. number of fixed telephone lines) can be replaced by new ones (e.g. number of smartphones) that better reflect the technological transformation.

From a normative perspective, our approach should also highlight the importance of contextuality in the discussion of the digital revolution. In times where data informing about the state of artificial intelligence, automation and other technological trends is available in abundance, a country's technological competitiveness is often scrutinized separately from its overall socioeconomic development. Stressing the complementarity between technological transformation and social adaptiveness, our approach is thus also an attempt to add a socioeconomic angle to this technocentric view. However, while our framework allows a quantitative analysis of technological and socioeconomic change, it does certainly not replace studies of technological revolutions based on historical accounts and appreciative theorizing. It rather attempts to supplement conventional measures of economic performance by a systemic approach and reveals broad patterns of socioeconomic change accompanying the current technology trends.

Acknowledgements Open access funding provided by Austrian Science Fund (FWF). This article is based on research undertaken in the scope of project SMART hosted at the Graz Schumpeter Centre and funded by the Austrian Science Fund [P 30434-G27]. The authors especially thank the referee and the editor of this special issue for the perceptive and most constructive comments on earlier versions of this manuscript.

\section{Compliance with ethical standards}

Conflict of interest On behalf of all authors, the corresponding author states that there is no conflict of interest.

Open Access This article is distributed under the terms of the Creative Commons Attribution 4.0 International License (http://creativecommons.org/licenses/by/4.0/), which permits unrestricted use, distribution, and reproduction in any medium, provided you give appropriate credit to the original author(s) and the source, provide a link to the Creative Commons license, and indicate if changes were made.

\section{Appendix}

See Tables 1 and 2 here. 
Table 1 Indicators related to ICT and digitalization and their respective assignment to source and target nodes in the SE-structure

\begin{tabular}{|c|c|c|c|c|}
\hline No. & Variable & Data source & Source node & Target node \\
\hline 1 & Internet access in schools & $\begin{array}{l}\text { World Economic Forum [GCI] } \\
\text { (2016a) }\end{array}$ & Infrastructure & Education \\
\hline 2 & $\begin{array}{l}\text { Individuals using } \\
\text { internet }\end{array}$ & $\begin{array}{l}\text { International Telecommunica- } \\
\text { tion Union [ITU] (2017) }\end{array}$ & Infrastructure & Infrastructure \\
\hline 3 & $\begin{array}{l}\text { Fixed broadband internet } \\
\text { subscriptions }\end{array}$ & ITU & Infrastructure & Infrastructure \\
\hline 4 & $\begin{array}{l}\text { International internet } \\
\text { bandwidth }\end{array}$ & ITU & Infrastructure & Infrastructure \\
\hline 5 & $\begin{array}{l}\text { Mobile broadband sub- } \\
\text { scriptions }\end{array}$ & ITU & Infrastructure & Infrastructure \\
\hline 6 & E-participation index & $\begin{array}{l}\text { United Nations Department of } \\
\text { Economic and Social Affairs } \\
\text { [UN EGOV] (2017) }\end{array}$ & Policy structure & Capital (social) \\
\hline 7 & ICT service exports & World Bank & Production & Performance \\
\hline 8 & Secure internet servers & World Bank (2016) & Infrastructure & Infrastructure \\
\hline 9 & $\begin{array}{l}\text { Patent applications in } \\
\text { ICT (PCT) }\end{array}$ & OECD [OECD Stat] (2017) & Technology & Production \\
\hline 10 & $\begin{array}{l}\text { Patent applications in } \\
\text { Nanotechnology (PCT) }\end{array}$ & OECD Stat & Technology & Production \\
\hline 11 & $\begin{array}{l}\text { Use of virtual social } \\
\text { networks }\end{array}$ & $\begin{array}{l}\text { World Economic Forum [NRI] } \\
(2016 \mathrm{~b})\end{array}$ & Infrastructure & Infrastructure \\
\hline 12 & $\begin{array}{l}\text { ICT use for business-to- } \\
\text { business transactions }\end{array}$ & NRI & Infrastructure & Production \\
\hline 13 & $\begin{array}{l}\text { Business-to-consumer } \\
\text { internet use }\end{array}$ & NRI & Infrastructure & Capital (social) \\
\hline 14 & $\begin{array}{l}\text { Importance of ICT to } \\
\text { government vision }\end{array}$ & NRI & Policy structure & Infrastructure \\
\hline 15 & $\begin{array}{l}\text { Government success in } \\
\text { ICT promotion }\end{array}$ & NRI & Policy structure & Infrastructure \\
\hline 16 & $\begin{array}{l}\text { Impact of ICT on busi- } \\
\text { ness models }\end{array}$ & NRI & Infrastructure & Production \\
\hline 17 & $\begin{array}{l}\text { Impact of ICT on new } \\
\text { organizational models }\end{array}$ & NRI & Infrastructure & Firm management \\
\hline 18 & $\begin{array}{l}\text { Impact of ICT on access } \\
\text { to basic services }\end{array}$ & NRI & Infrastructure & Capital (social) \\
\hline 19 & $\begin{array}{l}\text { ICT use and government } \\
\text { efficiency }\end{array}$ & NRI & Infrastructure & Policy structure \\
\hline 20 & Laws relating to ICT & NRI & Public policy & Infrastructure \\
\hline
\end{tabular}




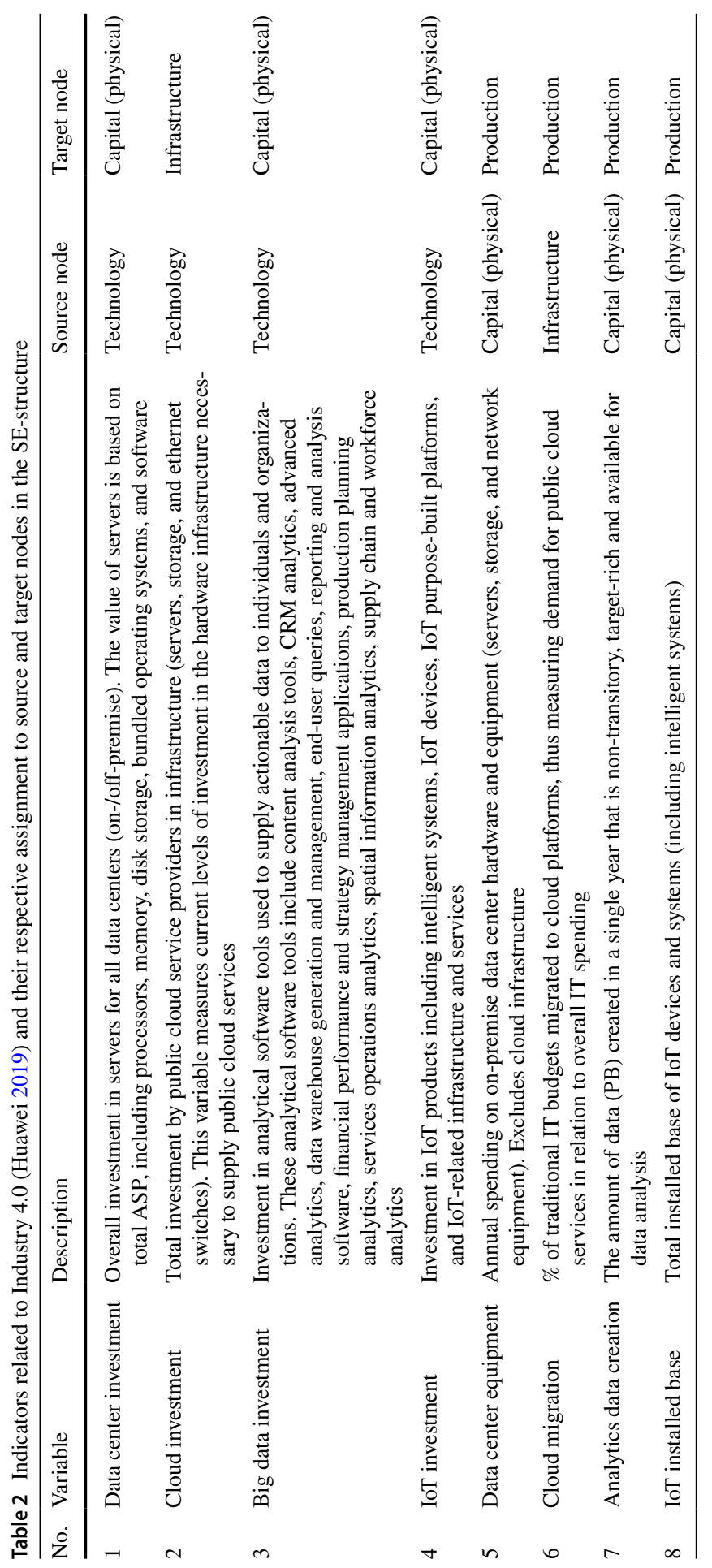




\section{References}

Autor, D. H. (2015). Why are there still so many jobs? The history and future of workplace automation. Journal of Economic Perspectives, 29(3), 3-30.

Borgatti, S. P., \& Everett, M. G. (1997). Network analysis of 2-mode data. Social Networks, 19, $243-269$. Brynjolfsson, E., \& McAfee, A. (2014). The second machine age. New York: Norton.

Dosi, G. (1982). Technological paradigms and technological trajectories. The determinants and directions of technical change. Research Policy, 11(3), 147-162.

European Commission [EC]. (2018). Digital transformation scoreboard 2018. EU businesses go digital: Opportunities, outcomes and uptake. https://ec.europa.eu/growth/tools-databases/dem/monitor/sites/ default/files/Digital\%20Transformation\%20Scoreboard\%202018_0.pdf. Accessed 4 Apr 2019.

Everett, M. G., \& Borgatti, S. P. (2012). The dual-projection approach for two-mode networks. Social Networks, 35, 204-210.

Frank, M.R., Autor, D., Bessen, J.E., Brynjolfsson, E., Manuel Cebrian, M., et al. (2019). Toward understanding the impact of artificial intelligence on labor. PNAS, 116(14), 6531-6539. https://www. pnas.org/content/pnas/early/2019/03/21/1900949116.full.pdf.

Freeman, C., Clark, J., \& Soete, L. (1982). Unemployment and technical innovation. A study of long waves and economic development. London: Frances Pinter.

Frey, C. B., \& Osborne, M. A. (2017). The future of employment: How susceptible are jobs to computerisation? Technological Forecasting and Social Change, 114, 254-280.

Geels, F. W., \& Schot, J. (2007). Typology of sociotechnical transition pathways. Research Policy, 36(3), 399-417.

Guillaume, J. L., \& Latapy, M. (2006). Bipartite graphs as models of complex networks. Physica A, 371, $795-813$.

Harary, F., \& Lipstein, B. (1962). The dynamics of brand loyalty: A Markovian approach. Operations Research, 10(1), 19-40.

Hartmann, D., Guevara, M. R., Jara-Figueroa, C., Aristarán, M., \& Hidalgo, C. A. (2017). Linking economic complexity, institutions, and income inequality. World Development, 93, 75-93.

Hsu, A., \& Zomer, A. (2016). Environmental Performance Index. http://epi2016.yale.edu/. Accessed 9 Oct 2017.

Huawei (2019). Global Connectivity Index. Country Profile. https://www.huawei.com/minisite/gci/en/ country-profile.html. Accessed 30 Mar 2019.

International Telecommunication Union [ITU] (2017). ICT Statistics. https://www.itu.int/en/ITU-D/Stati stics/Pages/default.aspx. Accessed 21 Jun 2018.

Kemeny, J., \& Snell, J. (1976). Finite Markov chains. New York: Springer.

Lipsey, R.G. (1999). Sources of continued long-run economic dynamism in the 21st century. In OECD (Ed.), The future of the global economy: Towards a long boom? (pp. 33-76). https://www.oecd.org/ futures/35394025.pdf. Accessed 20 March 2019.

Lipsey, R., Carlaw, K., \& Bekar, C. (2005). Economic transformations. General purpose technologies and long-term economic growth. New York: Oxford University Press.

Miller, R., \& Blair, P. (2009). Input-output analysis: Foundations and extensions. Cambridge: Cambridge University Press.

Mokyr, J. (1990). The lever of riches. Technological creativity and economic progress. New York: Oxford University Press.

OECD (2008). Handbook on constructing composite indicators. Methodology and user guide. https:// www.oecd.org/sdd/42495745.pdf. Accessed 20 Mar 2019.

OECD [OECD Stat] (2017). OECD.Stat. Patents by technology. https://stats.oecd.org/Index.aspx?DataS etCode=STANI4_2016. Accessed 28 Jul 2018.

Perez, C. (1983). Structural change and the assimilation of new technologies in the economic and social system. Futures, 15(5), 357-375.

Perez, C. (2002). Technological revolutions and financial capital. Cheltenham: Edward Elgar.

Perez, C. (2010). Technological revolutions and techno-economic paradigms. Cambridge Journal of Economics, 34(1), 185-202.

Perez, C. (2013). Unleashing a golden age after the financial collapse: Drawing lessons from history. Environmental Innovation and Societal Transitions, 6, 9-23. 
Peris-Ortiz, M., Ferreira, J. J. M., \& Fernandes, C. I. (2018). Do total early-stage entrepreneurial activities (TEAs) foster innovative practices in OECD countries? Technological Forecasting and Social Change, 129, 176-184.

Reinert, E.S., Endresen, S., Ianos, I., \& Saltelli, A. (2016). The Future of Economic Development between Utopias and Dystopias. The Other Canon Foundation and Tallinn University of Technology Working Papers in Technology Governance and Economic Dynamics 67, TUT Ragnar Nurkse Department of Innovation and Governance. http://technologygovernance.eu/files/main//2016071109 431515.pdf. Accessed 20 Mar 2019.

Schot, J., \& Kanger, L. (2018). Deep transitions: Emergence, acceleration, stabilization and directionality. Research Policy, 47, 1045-1059.

Schwab, K., \& Sala-i-Martin, X. (2017) (eds.). The Global Competitiveness Report 2017-2018. http:// www3.wefor um.org/docs/GCR2017-2018/05FullReport/TheGlobalCompetitivenessReport 2017\%E2\%80\%932018.pdf. Accessed 16 Feb 2018.

Strohmaier, R., Schuetz, M., \& Vannuccini, S. (2019). Going beyond by inspecting the ties between: A structuralist view on measuring technological transformation and socioeconomic development. Mimeo.

United Nations Department of Economic and Social Affairs [UN EGOV] (2017). UN E-Government Knowledgebase, Division for Public Institutions and Digital Government. https://publicadministr ation.un.org/egovkb/en-us/Data-Center. Accessed 21 Jun 2018.

von Tunzelmann, G. N. (1997). Innovation and industrialization: A long-term comparison. Technological Forecasting and Social Change, 56, 1-23.

World Bank (2016). World Bank Open Data, http://data.worldbank.org/indicator/NY.GDP.MKTP. KD.ZG?end=2014\&name_desc=false\&start=1961. Accessed 25 Jun 2018.

World Economic Forum [GCI] (2016a). The global competitiveness index historical dataset. http://repor ts.weforum.org/global-competitiveness-index-2016-2017/downloads/. Accessed 10 Jul 2018.

World Economic Forum [NRI] (2016b). Networked readiness index. Historical dataset (2012-2016). http://reports.weforum.org/global-information-technology-report-2016/networked-readiness-index/. Accessed Jun 2018.

Zweig, K. A., \& Kaufmann, M. (2011). A systematic approach to the one-mode projection of bipartite graphs. Social Networks Analysis and Mining, 1, 187-218.

Publisher's Note Springer Nature remains neutral with regard to jurisdictional claims in published maps and institutional affiliations. 